\section{Automated external defibrillator skills among lay people in the region of Koroska: a pilot study}

VESNA STROPNIK • ZALIKA KLEMENC-KETIS
ZALIKA KLEMENC KETIS ( $\square$ )

Department of Family Medicine

Maribor and Ljubljana Medical School

Taborska ulica 8, 2000 Maribor

Poljanski nasip 58

1000 Ljubljana, Slovenia

E-mail: zalika.klemenc-ketis@uni-mb.si

VESNA STROPNIK

Ravne na Koroškem Health Centre

Ravne na Koroškem, Slovenia

\begin{abstract}
Background. In the region of Koroška, there are more and more public spaces equipped with automated external defibrillators which can be used by a witnessed bystander. The aim of this study was to gain insight into the skills required for using automated external defibrillators.

Methods. This was a cross-sectional survey conducted in two family medicine practices. We included volunteers who visited their family doctor during a period of four days. Skills were assessed in a virtual setting using a plastic manikin.

Results. There were 107 participants in the sample, $60.0 \%$ were women. Average age of the sample was $47.6 \pm 16.8$ years. In the practical part (skills testing), the participants earned 2.7 points from a total of 5 points. Younger participants and those who attended a course in basic life support, in the past 10 years, had a significantly higher score.

Conclusion. Lay people need more education regarding skills for using automated external defibrillators.
\end{abstract}

Key words: automated external defibrillator, basic life support, lay people, survival, cardiac arrest

\section{Introduction}

Out-of-hospital survival rates for sudden cardiac arrest are still low. (1) Early defibrillation is one of the most important factors influencing the chances of survival. $(2,3)$ Therefore, lay people should also have the knowledge and skills to perform defibrillation. Namely, bystander reactions on the scene are crucial and can significantly improve the survival of cardiac arrest victims. $(4,5)$

In Slovenia, lay people usually acquire cardio-pulmonary resuscitation (CPR) knowledge and skills in obligatory first aid courses which are a part of driver licensing requirements. Over the last three years they are also taught to use automatic external defibrillators (AED). However, a recent study showed that lay public in Slovenia had poor CPR knowledge. This was especially the case among untrained individuals. (6) The aim of this study was to determine the level of AED skills among lay people in one region of Slovenia.

\section{Materials and methods}

This was a cross-sectional study conducted in two family medicine practices in the Koroška region of Slovenia (northern part of Slovenia). The Koroska region covers $1,042 \mathrm{~km}^{2}$ and has 76,000 inhabitants. There are two major towns in this region: Slovenj Gradec and Ravne na Koroškem. There are four primary care health centres in the Koroska region. The study took place in two family medicine practices in the health centre of Ravne na Koroškem. Each family physician working in the practice has on average 2,000 patients on their list. A consecutive sample of patients who attended their family doctor during a period of four days in December 2011 was included. We approached 540 patients. To be included in the study, participants had to be 18 years of age or older, without prior formal medical education, and had to orally consent to participate in the study after being informed. Exclusion criteria included: medical education, neurological problems, physical disability and problems with mental development.

The data were collected using a demographic data questionnaire, and a scale for assessing the level of AED skills. Each participant was asked to fill out the questionnaire. Then, he or she was asked to demonstrate the use of an AED on a manikin (Laerdal Resuscie Anne CPR Torso) according to a previously developed scenario: "You are waiting at the bank when suddenly a man in front of you collapses. You find out that this person is not breathing nor has a pulse. The bank worker brings an AED. What will you do? Demonstrate its use on the manikin." His or her performance was assessed by one of the authors (Vesna Stropnik).

We used a Zoll AED plus defibrillator (AED Zoll plus trainer 2). Participants had to switch on the defibrillator, open its cover, appropriately place the electrodes on the manikin and check for 
Table 1. Participants' performance on the automatic external defibrillator (AED) practice skills' test.

\begin{tabular}{lll}
\hline Step & $\begin{array}{l}\text { Number of participants who } \\
\text { performed the step correctly }\end{array}$ & $\begin{array}{l}\text { Percentage of participants } \\
\text { performed the step correctly }\end{array}$ \\
\hline $\begin{array}{l}\text { Switched on the AED } \\
\text { Opened the AED's cover }\end{array}$ & 98 & 91.6 \\
$\begin{array}{l}\text { Appropriately placed the electrodes on } \\
\text { the manikin }\end{array}$ & 88 & 82.2 \\
$\begin{array}{l}\text { Checked for safety prior to pressing the } \\
\text { button for defibrillation }\end{array}$ & 4 & 20.6 \\
\begin{tabular}{l} 
Pressed the button for defibrillation \\
\hline
\end{tabular} & 80 & 3.7 \\
\hline
\end{tabular}

safety prior to pressing the button for defibrillation. Each of these five steps was assessed and scored by one point if it was correct or by zero points if it was wrong. The final score was a minimum of 0 points and a maximum of 5 points. We performed statistical analysis using SPSS v. 13.0 statistical program (SPSS Inc., Chicago, IL, USA). We performed a descriptive and bivariate analysis. In the latter, we used hi-square test and independent t-test. We regarded $p<$ 0.05 as a significant value.

\section{Results}

Demographic characteristics

Out of 540 invited patients, 107 decided to participate in the study $(19.8 \%$ response rate). Mean age was $47.6 \pm 16.8$ years. There were 64 (60.0\%) women in the sample. Most respondents (61, $57.0 \%)$ had completed secondary school, 25 (23.4\%) had finished primary school and 21 (19.6\%) had graduated from university. In the past 10 years, 32 (29.9\%) participants had completed a course in CPR.

AED skills

The mean number of points on the AED skills assessment scale was 2.7 \pm 1.2 . All five steps were performed by $2(1.9 \%)$ participants, four steps by 22 (20.6\%) participants and three steps by 56 (52.3\%) participants (table 1).

Age was negatively correlated with the number of points on the skills' test ( $r=$ -0.462, $p<0.001$ ). Participants who attended a course on CPR in the past 10 years had significantly more points on the skills' test when compared to others (3.1 \pm 1.0 vs. $2.6 \pm 1.2$ points; $p=0.024)$.

\section{Discussion}

Our pilot study showed that lay people had average skills in using AED. The AED skills seem to be associated with younger age and prior attendance to CPR courses.

However, only $2 \%$ correctly performed all five steps of defibrillation with an AED.

A Slovenian study on CPR knowledge among lay people showed that only $1.2 \%$ of the 500 people in the sample knew the correct frequency of chest compressions, only $2.2 \%$ the correct ratio between ventilation and chest compressions and $37.6 \%$ of them knew the correct spot for chest compressions. (6) However, this study did not assess skills but only knowledge.

In a recent study from Germany, participants performed CPR on a manikin (without the usage of AED). (7) The results showed that none of the 89 participants correctly performed the whole CPR algorithm. However, performance seemed to be associated with attendance to a CPR course in the 10 years prior to the study. This was also found in our pilot study and points to the importance of regular and continuous attendance of CPR courses. A study from New Zealand (8) compared the use of three different AEDs by 24 lay people with no prior exposure to the use of AED. It showed that the majority of subjects safely and effectively delivered defibrillation shocks without any prior training and within quite acceptable times. Several studies showed that lay persons can use AEDs quickly and without specific instructions. (9-11)

Previous studies $(10,11)$ showed that brief training significantly improved the performance of lay persons regarding the use of AED. As the results of our study showed, there is a need for education of lay people regarding the use of AED in CPR.

This was a pilot study with many limitations. We included only one Slovenian region and only a small number of family practice visitors. In addition, the response rate was also low mainly due to the fear of using AED and a lack of time. So, the results are not representative not only for the region of Koroska, but also for Slovenia. As we included only people who visited their family physicians, this can be an additional source of selection bias. So, our results cannot be generalized to the whole population. However, this study provided us with important data regarding the skills of lay persons in the use of AED and will serve as a good starting point for further research planning.

Obviously, there is a need for additional studies. First, a study should evaluate the AED skills in a representative sample of the general Slovenian population. Then, a prospective intervention study should be performed with a group of lay people receiving a course on CPR including AED skills and a control group. This study should evaluate the shortand long-term effect of such courses on CPR knowledge and AED skills. 


\section{ACKNOWLEDGEMENTS}

We thank Peter Kordez for lending us an AED. We thank Ravne na Koroskem Health Centre for lending us the manikin.

\section{REFERENCES}

1. Nichol G, Thomas E, Callaway CW, Hedges J, Powel JL, Aufderheide TP, et al. Regional variation in out of hospital cardiac arrest incidence and outcome. JAMA 2008;300:1423-31.

2. Valenzuela TD, Roe DJ, Cretin S, Spaite DW, Mesilin HW, Clark LL, et al. Estimating effectivness of cardiac arrest interventions: a logistic regression survival model. Circulation 1997;96:3308-13.

3. Hayashi $\mathrm{Y}$, Hiraide A, Morita H. Three year longitudinal study for out-of hospital cardiac arrest in Osaka Prefecture. Resuscitation 2004;63:161-6.

4. Hazinski MF, Idris AH, Kerber RE, Epstein A, Atkins D, Tang W, et al. Lay rescuer automated external defibrillator ("public access defibrillation") programs: lessons learned from an international multicenter trial: advisory statement from the American Heart Association Emergency Cardiovascular Committee; the Council on Cardiopulmonary, Perioperative, and Critical Care; and the Council on Clinical Cardiology. Circulation 2005;111:3336-40.

5. Valenzuela TD, Roe DJ, Cretin S, Spaite DW, Larsen MP. Estimating effectiveness of cardiac arrest interventions: a logistic regression survival model. Circulation 1997;96:3308-13.

6. Rajapakse R, Noč M, Kersnik J. Public knowledge of cardiopulmonary resuscitation in Republic Slovenia. Wien Klin Wochenschr 2010;122:667-72.

7. Piepho T,Resch N, Heid F, Werner C, Noppens RR. Lay basic life support: the current situation in a medium-sized German town. Emerg Med 2011;28:786-9.

8. Earnes P, Larsen PD, Galletly DC. Comparison of ease of use of three automated external defibrillators by untrained lay people. Resuscitation 2003;58:25-30.

9. Beckers S, Fries M, Bickenbach J, Derwall M, Kuhlen R, Rossaint R. Minimal instructions improve the performance of layperons in the use of semiautomatic and automatic external defibrillators. Crit Care 2005;9:R110-6.

10. Woollard M, Whitfield R, Smith A, Colguhoun M, Newcombe RG, Vetteer N, et al. Skill acquisition and retention in automated external defibrillator (AED) use and SPR by lay respondents: a prospective study. Resuscitation 2004;60:17-28.

11. Mitchell KB, Gugerty L, Muth E. Effects of brief training on use of automated external defibrillators by people without medical expertise. Hum Factors 2008;50:301-10. 